\title{
The Effect of Job Nature on Job Adjustment of Nurses in Hospital Affiliated to Kashan University of Medical Sciences
}

\author{
Hamid Rahimi
}

1. Associate Professor, School of Humanities, University of Kashan, Kashan, Iran

\begin{tabular}{|c|c|}
\hline Article Info & ABSTRACT \\
\hline $\begin{array}{l}\text { Received: 2020/04/25; } \\
\text { Accepted: 2020/07/10; } \\
\text { ePublished: 2020/10/15 }\end{array}$ & $\begin{array}{l}\text { Background and Objectives: Job adjustment is an important factor for the } \\
\text { successful employment of nurses. The job nature can be a factor influencing job } \\
\text { adjustment. The aim of the present study was to investigate the effect of job nature } \\
\text { on job adjustment among a sample of nurses. }\end{array}$ \\
\hline dof) 10.30699/jergon.8.2.17 & Methods: This cross-sectional study was conducted among 542 nurses working \\
\hline $\begin{array}{l}\text { Use your device to scan } \\
\text { and read the article online }\end{array}$ & $\begin{array}{l}\text { in hospitals affiliated to Kashan University of Medical Sciences. Using Cochran's } \\
\text { formula and stratified random sampling method, } 190 \text { nurses were selected as a } \\
\text { sample. Two standard and validated questionnaires were used for gathering data } \\
\text { associated with job nature and job adjustment. The reliability of the questionnaires } \\
\text { was estimated through Cronbach's alpha coefficient. Data analysis was performed at } \\
\text { both descriptive and inferential levels using SPSS } 22 \text {. }\end{array}$ \\
\hline 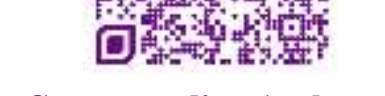 & $\begin{array}{l}\text { Results: Findings revealed that means of job nature }(70.43 \pm 45.07) \text { was higher than } \\
\text { average (60) and mean of job adjustment }(3.23 \pm 0.42) \text { was higher than average (3). }\end{array}$ \\
\hline $\begin{array}{l}\text { Corresponding Author } \\
\text { Hamid Rahimi } \\
\text { Associate Professor, School of } \\
\text { Humanities. University of }\end{array}$ & $\begin{array}{l}\text { Pearson correlation coefficient showed that there is a positive and significant } \\
\text { relationship between job nature and job adjustment }(\mathrm{r}=0.29) \text {. The regression coefficient } \\
\text { showed that the job nature was able to predict the job adjustment of nurses. }\end{array}$ \\
\hline Kashan, Kashan, Iran & $\begin{array}{l}\text { Conclusion: The average job nature and adjustment of nurses were favorable and } \\
\text { there was a positive relationship between job nature and job adjustment of nurses. }\end{array}$ \\
\hline $\begin{array}{l}\text { Email: } \\
\text { dr.hamid.rahimi@kashanu.ac.ir }\end{array}$ & $\begin{array}{l}\text { Therefore, in order to increase the adjustment of nurses, managers should pay more } \\
\text { attention to nurses' perceptions of their job characteristics and provide them with } \\
\text { diversity, feedback and the opportunity to create friendly relationships at work. }\end{array}$ \\
\hline
\end{tabular}

Keywords: Job nature, Job adjustment, Nurse

Copyright $\odot$ ( 2020, This is an original open-access article distributed under the terms of the Creative Commons Attribution-noncommercial 4.0 International License which permits copy and redistribute of the material just in noncommercial usages with proper citation.

\section{How to Cite This Article:}

Rahimi H. The Effect of Job Nature on Job Adjustment of Nurses in Hospital Affiliated to Kashan University of Medical Sciences. Iran J Ergon. 2020; 8 (2): 17-25 
تأثير ماهيت شغلى بر سازگًارى شغلى يرستاران در بيمارستان دانشعاه علوميزشكى كاشان

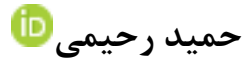

! . دانشيار و عضو هيات علمى دانشكده علوم انسانى، دانشكاه كاشان، كاشان، ايران

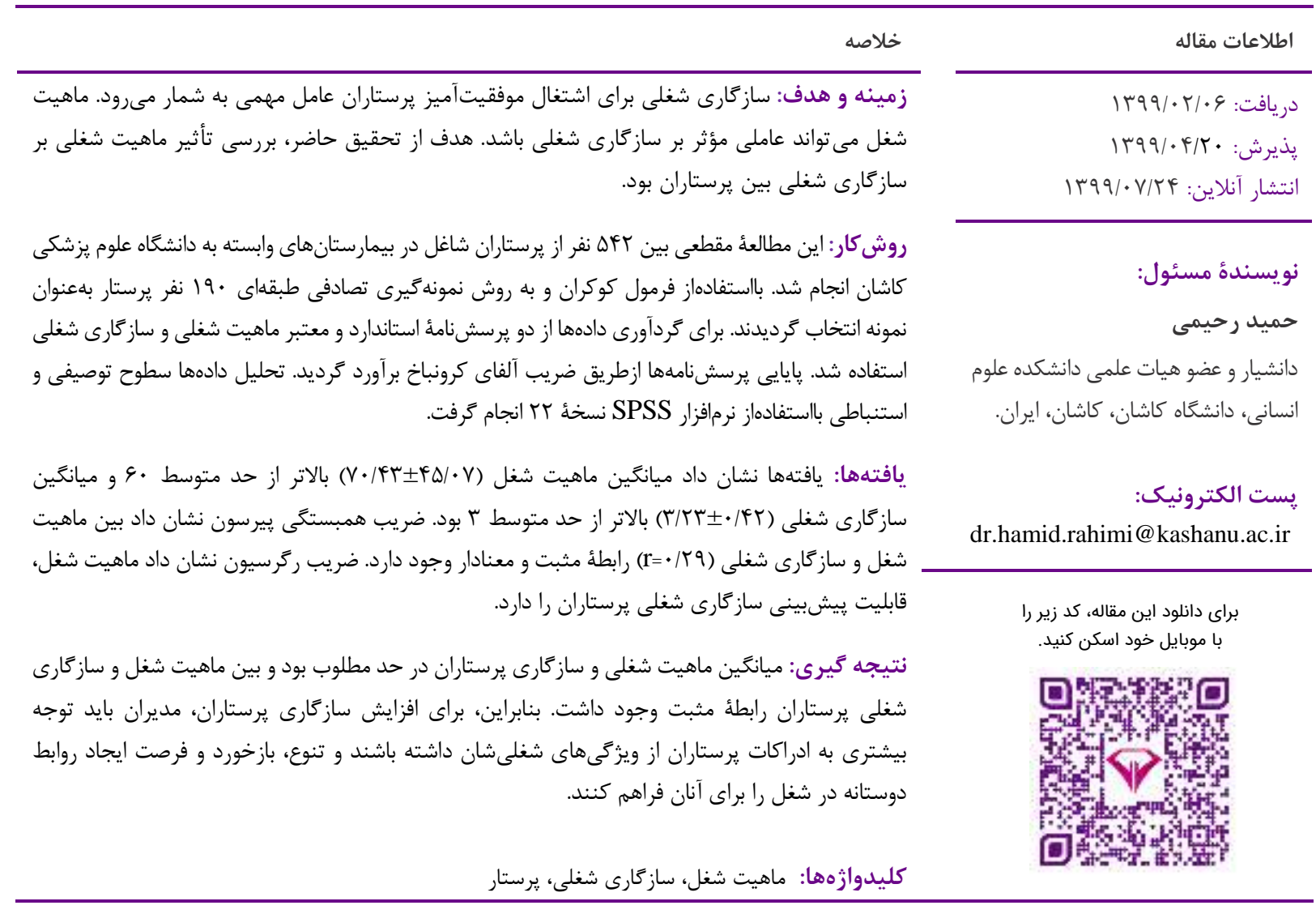

مقدمه

فشارهاى كارى اين گروه به اندازهاى افزايش مىيابد كه باعث

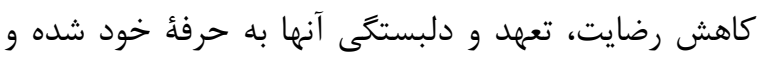
زمينه را براى ترك خدمت و رفتارهاى ديخر فراهم مىسازد

سازگارى شغلى، ازجمله عوامل مربوط به ايجاد هماهنگى در كار، افزايش بهرهورى و سودآورى كاركنان نسبت به سازمان، تعلق و وابستخى آنان به محيط كار، افزايش كميت و كيفيت كار، برقرارى روابط خوب و انسانى در محل كار، بالابردن روحيه، عشق و علاقه به كار است [ه].

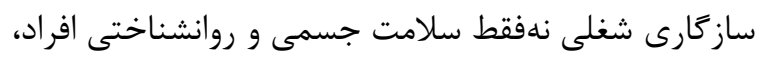
بلكه عملكرد شخصى و سازمانى آنها را نيز بهبود مىبخشد [9]. فرض اصلى در نظرئُ سازگًارى شغلى اين است كه فرد، خواهان دستيابى و حفظ ارتباط مثبت با محيط كارى است.
طبق نظر سازمان بهداشت جهانى، يرستاران ستون فقرات

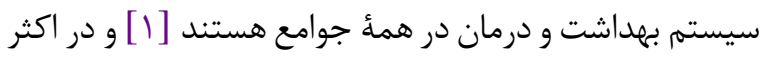
سازمانهاى مراقبت بهداشتى، يرستاران مهرمترين نيروى

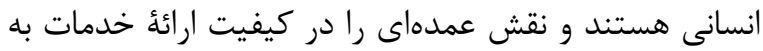
عهده دارند [r]. بنابراين، رضايت و كارايى آنان بهطور

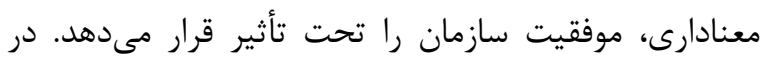
محيطهاى كارى بهداشت و درمان، يرستاران به دليل تماس با بيماران بدحال و فشار كارى بالا، مدام با مشكلات كارى و و

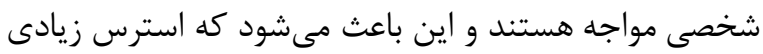
بر آنها وارد شده و ساز گارى شغلى آنها را تحت تأثير قرار دهد. بررسىها نشان مىدهند سو درصد يرستاران، مرتب تحت تأثير عوامل استرس زاى محيط كار قرار مى گيرند كه مى تواند

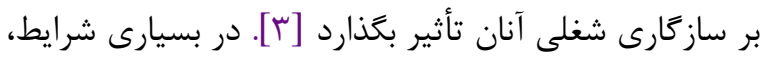




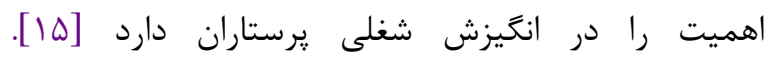
Taherpour

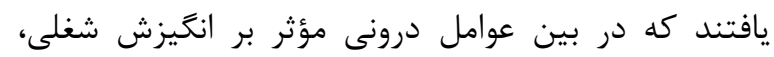

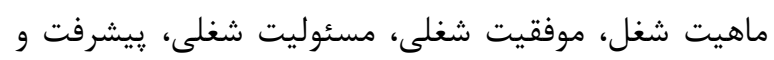

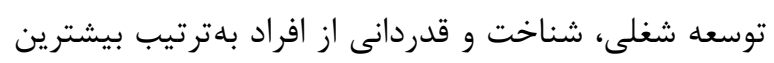

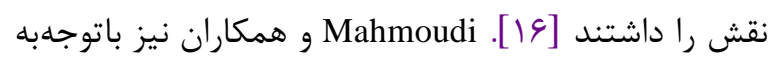

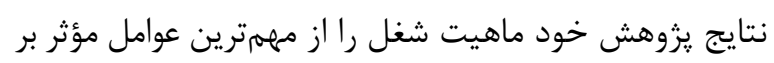

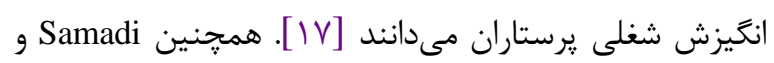

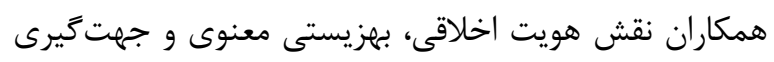

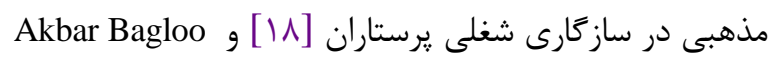

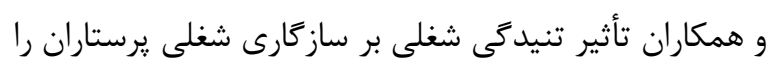

مؤثر و مهمم ارزيابى كردند [19].

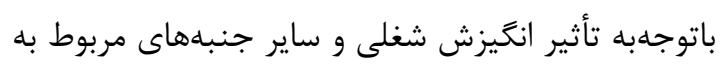

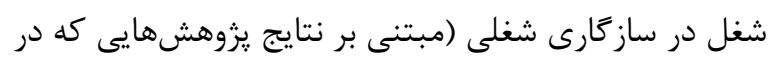

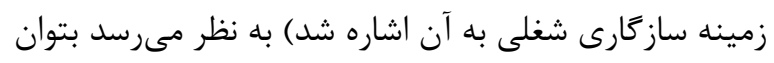

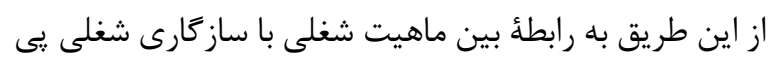

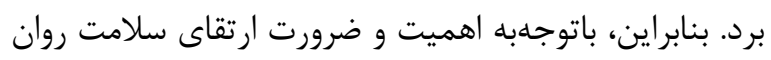

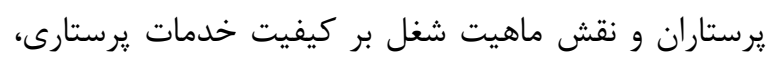

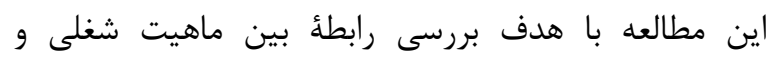

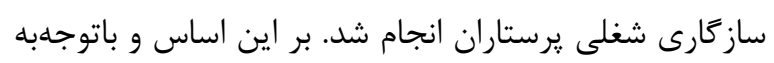

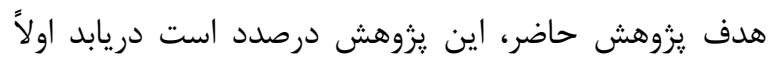

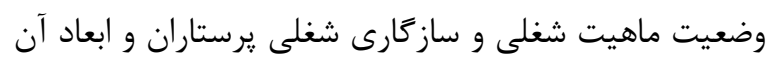

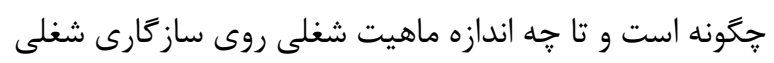
تأثير دارد؟

\section{روش كار}

نوع تحقيق ازنظر هدف كاربردى، ازنظر اجرا توصيفى

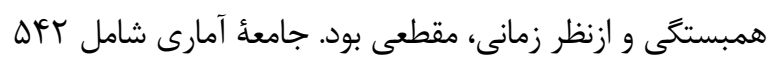

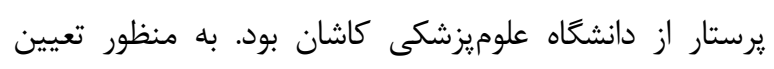

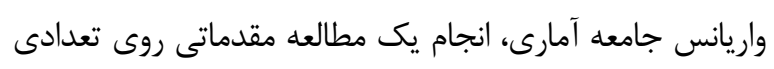

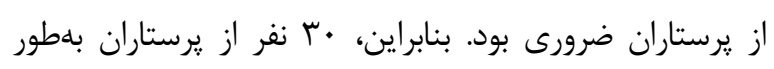

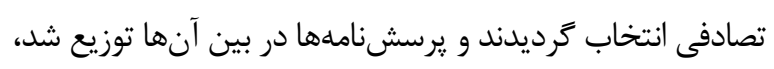

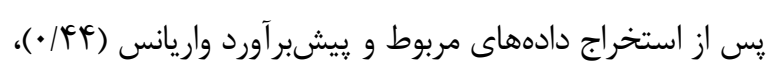

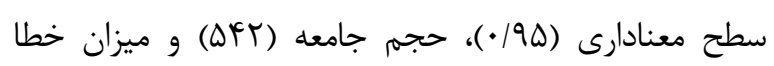

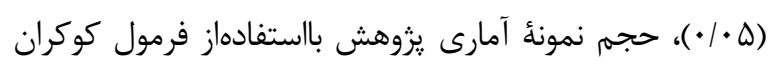

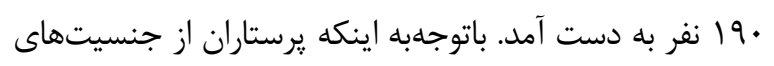

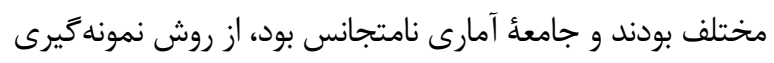

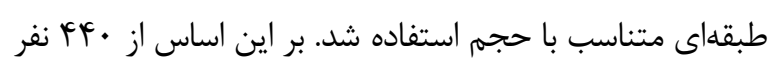

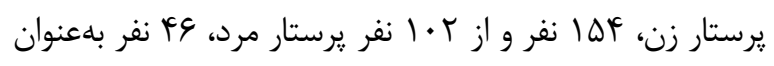

افراد، نيازهاىشان را وارد محيط كارى مى كنند و محيط كار

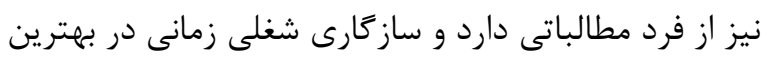

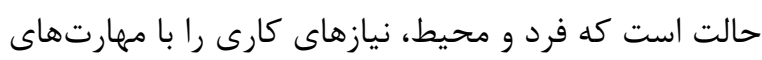

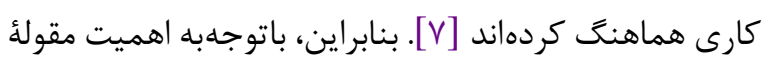

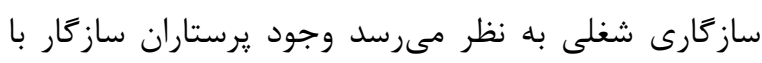

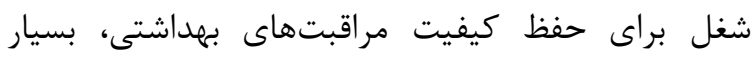

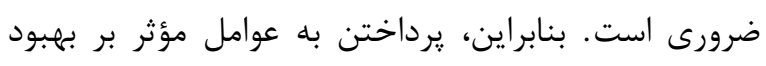

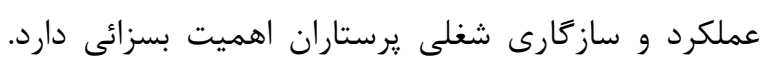

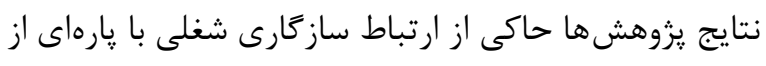

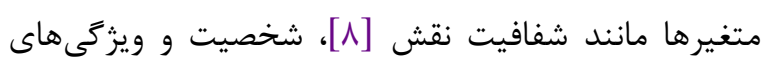

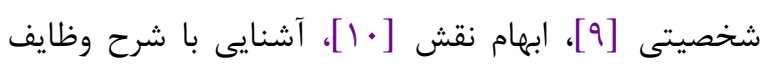

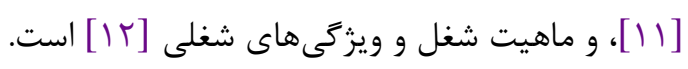

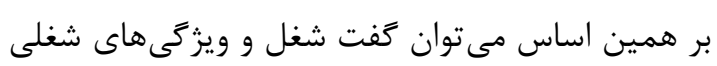

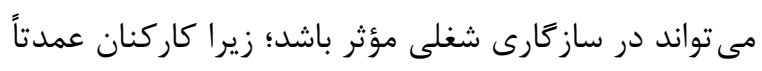

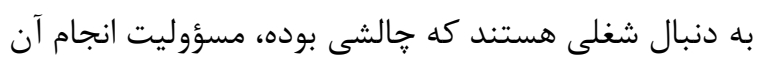

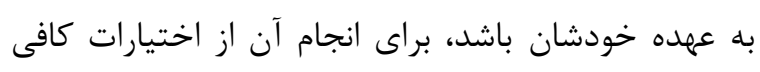

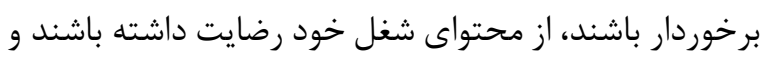

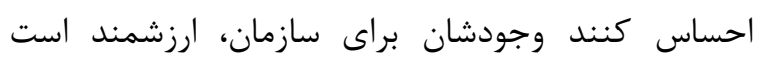

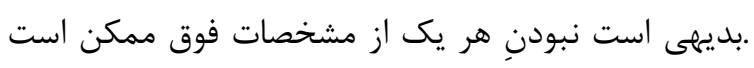
موجب نارضايتى فرد شود [1 أi]. Hackman

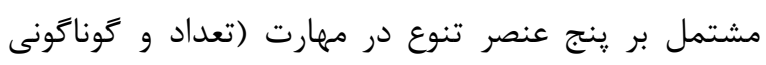

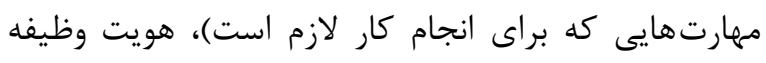
(ميزانى كه شاغل، يك كار را بهطور كامل انجام مى دهدد)،

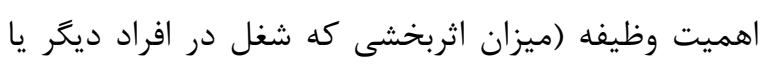

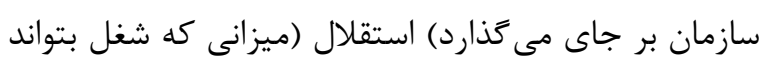

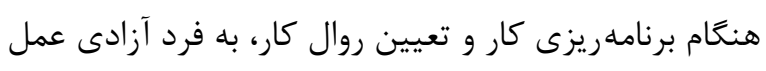

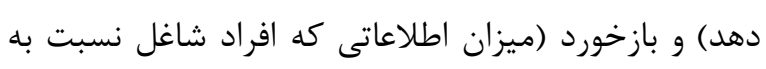

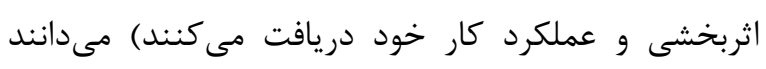

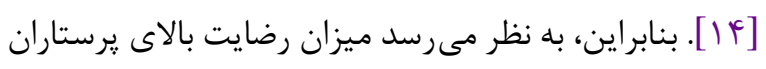

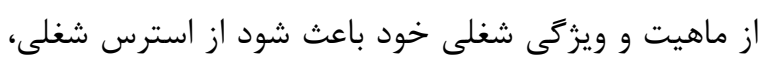

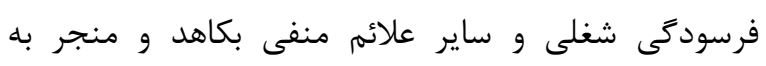

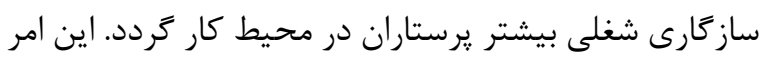

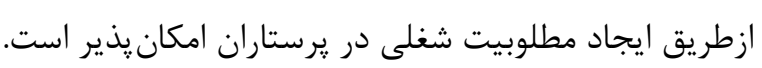

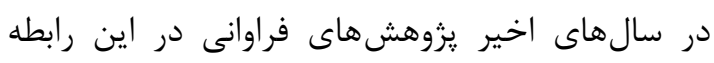

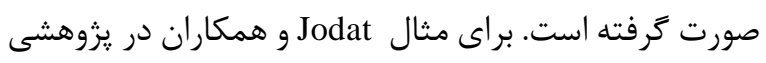

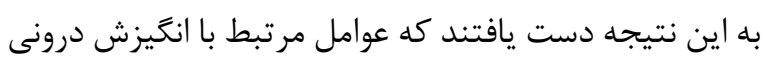
نسبت به عوامل بهداشتى بيرونى اهميت بيشترى در در ايجاد

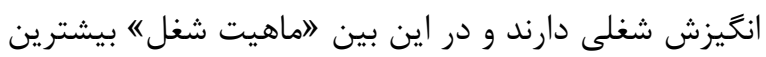


همجنين نمره ملاك براساس نمره ميانگين برابر سه و براساس

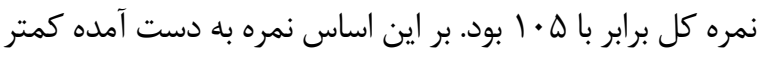

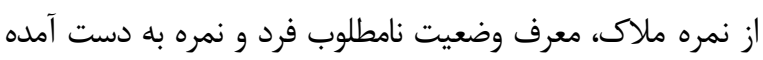

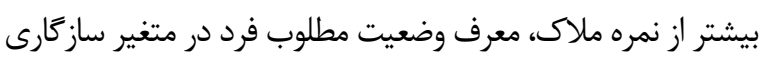

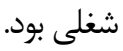
روايى محتوايى و سازء يرسشنامهها تأييد شد. در بخش برد

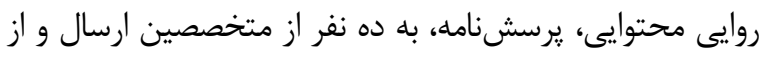

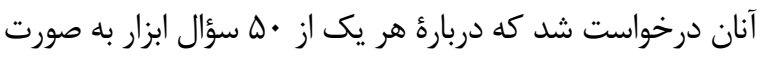

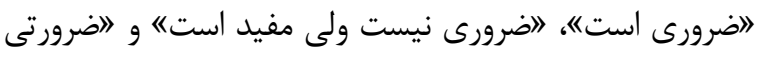

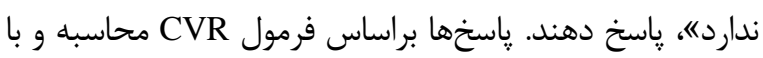

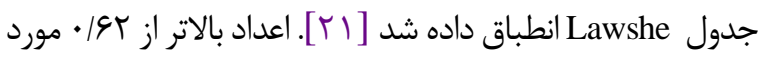

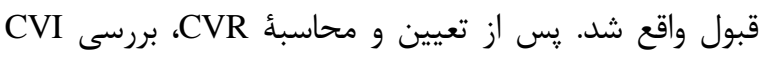

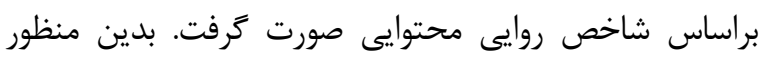

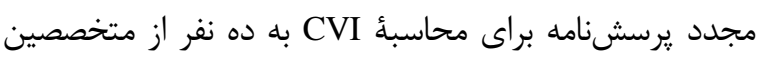

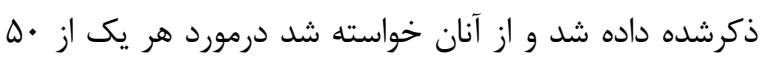

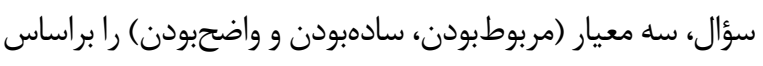

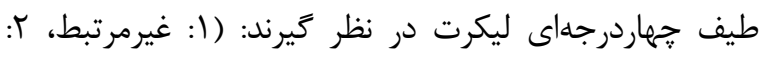

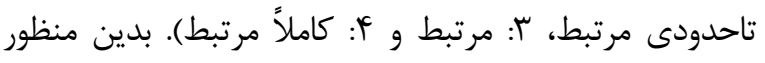

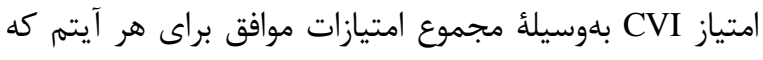

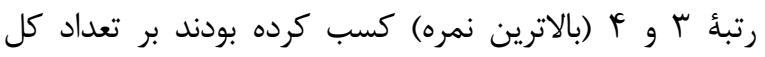

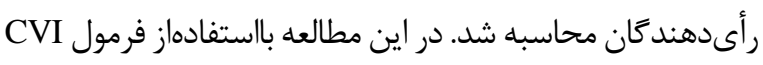

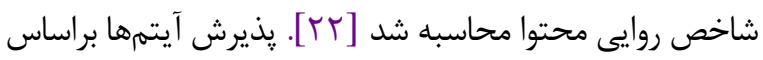

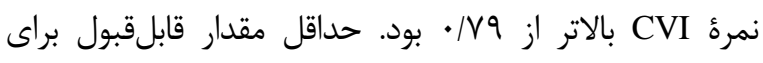

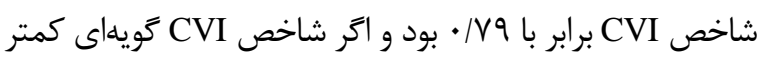

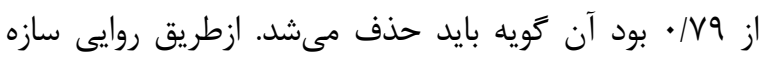

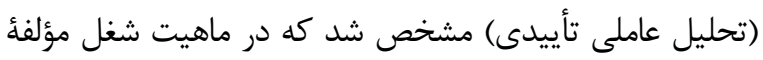

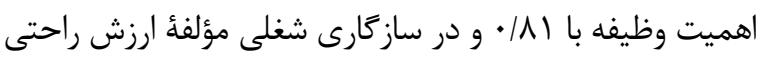

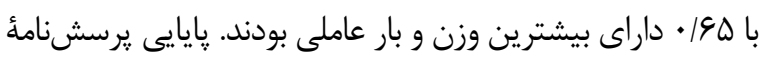

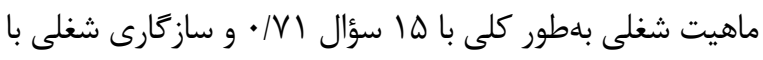

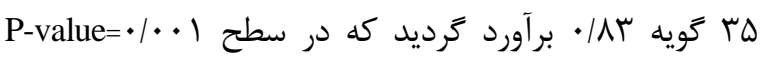

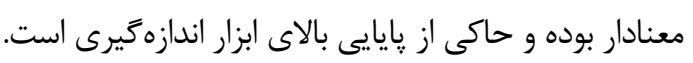

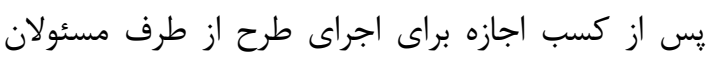

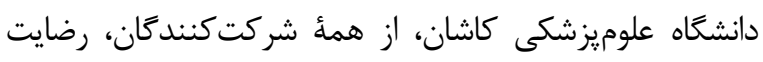

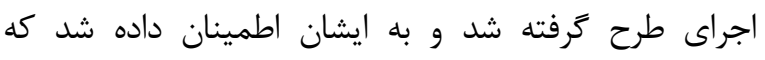

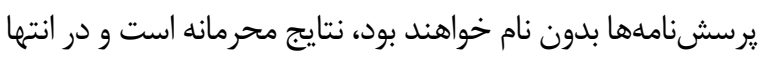

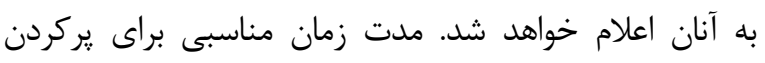

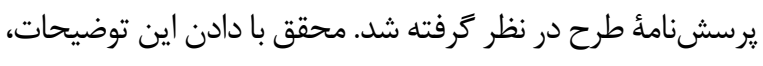

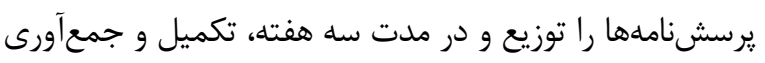
نمود. تحليل دادهها در دو سطح توصيفى (فراوانى، درصد،

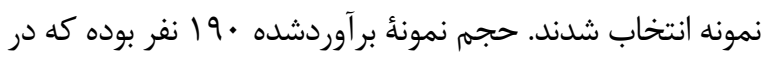

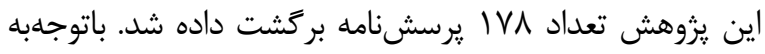

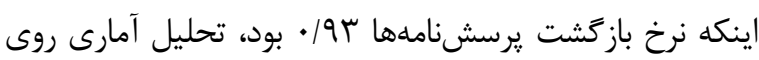

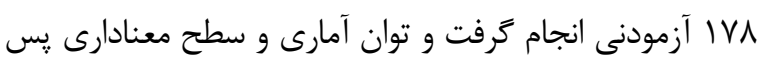

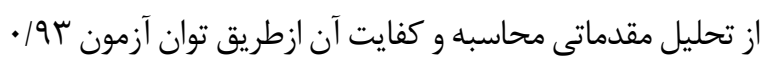

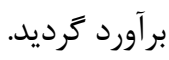
معيارهاى ورود تمايل به همكارى و رضايتمندى آنها

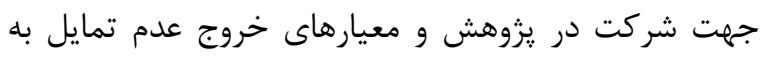

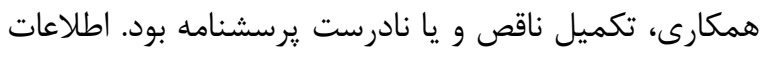

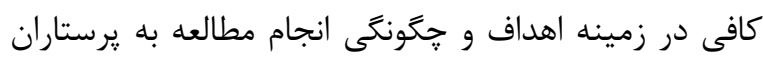

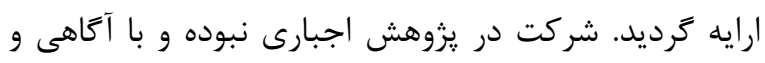

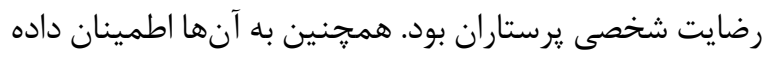

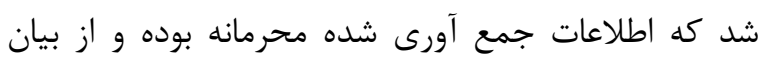

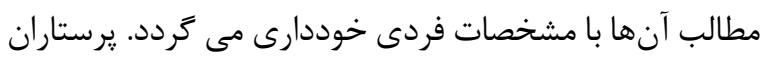

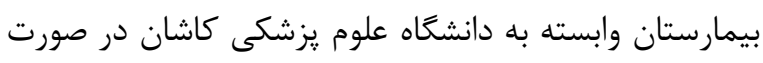

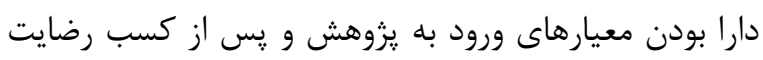

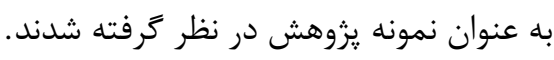

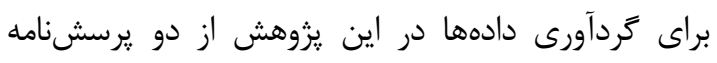

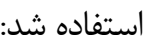

\section{الف: :رسشنامةٔ ماهيت شغل: يرسشنامئ استاندارد}

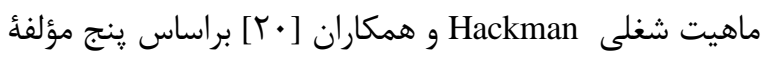

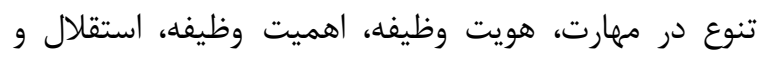

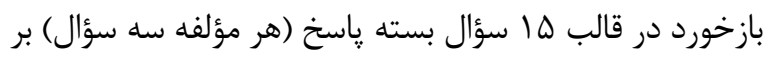

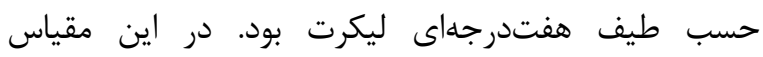

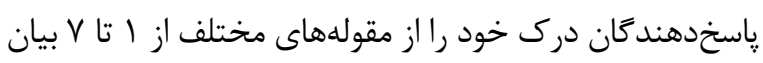

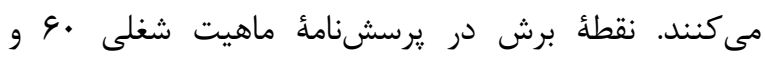

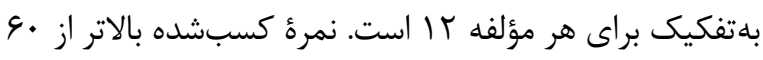

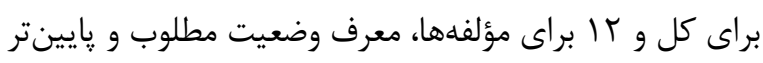

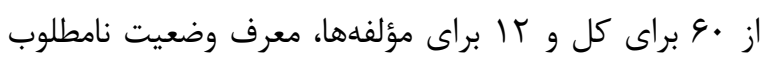

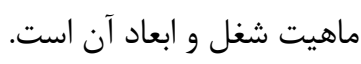

\section{ب) يرسشنامة سازَارى شغلى: يرسشنامة استاندارد}

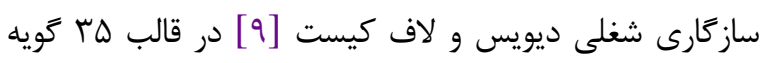

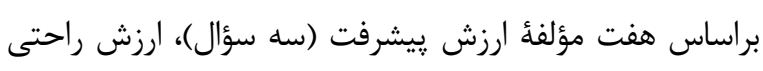

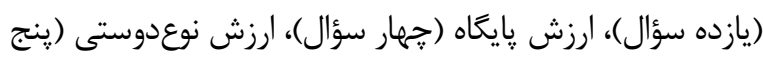

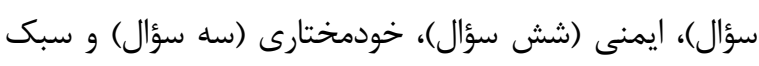

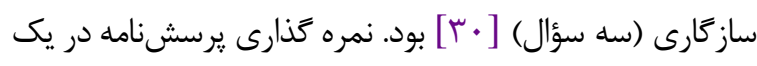

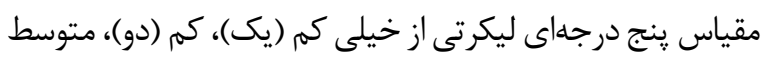

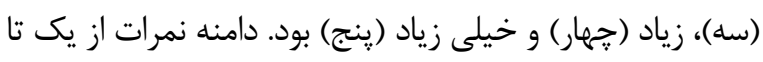

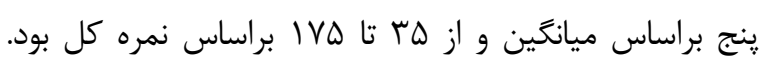


• ا مال، وضعيت استخدامى رسمى و ازنظر وضعيت أنأهل، متأهل بودند.

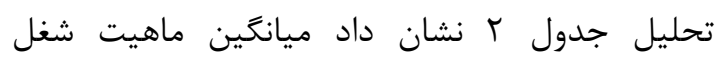

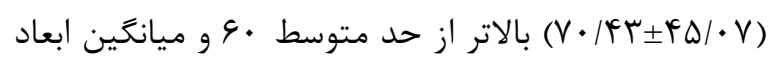

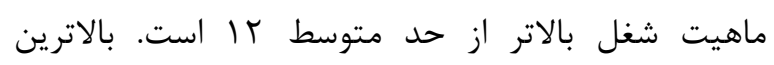

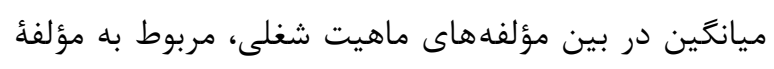

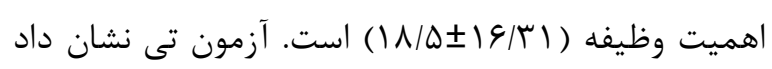

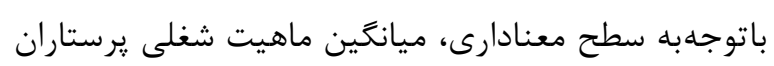

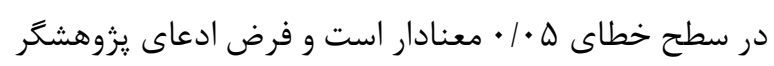
تأييد مى شود.
ميانگين و انحر افمعيار) و استنباطى (ضريب همبستخى بيرسون،

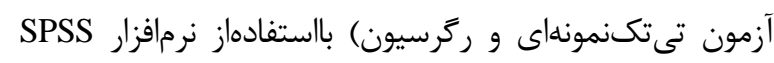

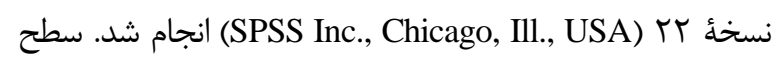
معنادارى در آزمون ها، هـ/P-value د در نظر كرفته شد.

بافته ها

در اين بخش، يافتههاى توصيفى و استنباطى يزوهش

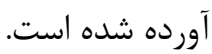
طبق جدول ا، از مجموع يرستاران كَروه نمونه، اكثر

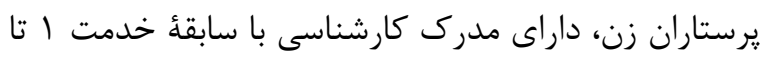

جدول ا. مشخصات فردى گروه نمونه

\begin{tabular}{|c|c|c|c|}
\hline درصد & فراوانى & سطوح & متغير \\
\hline$r \cdot$ & re & 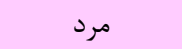 & \multirow{2}{*}{ جنسيت } \\
\hline$\wedge \cdot$ & IFT & زن & \\
\hline $9 \cdot$ & 19 & كارشناسى & \multirow{2}{*}{ مدرك تحصيلى } \\
\hline 1. & 11 & ارشد و بالاتر & \\
\hline TI & rV & ي يمانى & \multirow{4}{*}{ وضعيت استخدامى } \\
\hline V & it & 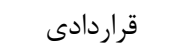 & \\
\hline$\Delta \varphi$ & १९ & رسمى & \\
\hline IV & r. & طرحى & \\
\hline$r \Delta$ & $i \Delta$ & مجرد & \multirow{2}{*}{ وضعيت تأهل } \\
\hline$V \Delta$ & س & متأهل & \\
\hline 9 & 19 & آىسىيو & \multirow{5}{*}{ بخش كارى } \\
\hline me & 9) & سىسىيو و آنثه & \\
\hline 19 & rᄉ & جراحى & \\
\hline $1 \cdot$ & 11 & سازمانى & \\
\hline r & $\Delta \omega$ & زايمان و اطفال & \\
\hline $9 \Delta$ & 119 & $1-1$ & \multirow{3}{*}{ سابقه خدمت (سال) } \\
\hline rt & $\Delta V$ & $11-r$ & \\
\hline r & $\Delta$ & • & \\
\hline
\end{tabular}

\begin{tabular}{|c|c|c|c|c|c|c|}
\hline $\mathbf{P}$ & درجه آزادى & $\mathbf{t}$ & ميانَين جامعه & ميانَين و انحرافاستاندارد & تعداد & متغير \\
\hline$\cdot 1 \cdot \cdot 1$ & IVV & $r \Delta / \cdot \varphi$ & ir & $I V / T \pm q N / T V$ & $I \vee \wedge$ & تنوع مهارت \\
\hline$\cdot 1 \cdot \cdot 1$ & IVV & $\mid Q / F F$ & ir & $|\Lambda / \Delta \pm| \varepsilon / T \mid$ & $I V \wedge$ & اهميت وظيفه \\
\hline$\cdot 1 \cdot \cdot 1$ & IVV & |N/As & ir & $|q / T \pm \varphi| / T V$ & $I V \wedge$ & هويت وظيفه \\
\hline$\cdot 1 \cdot \cdot 1$ & IVV & $\Delta / 9 F$ & it & $\mid r / \mathcal{F} \pm \Lambda T / \cdot V$ & $I \vee \wedge$ & استقلال \\
\hline$\cdot 1 \cdot \cdot 1$ & IVV & $r V / F$ & ir & $|V / r \pm \wedge| / \Lambda r$ & IVA & 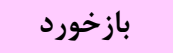 \\
\hline$\cdot 1 \cdot r$ & IVV & $r / \cdot q$ & q. & $V \cdot \mid F \Delta \pm F r / \cdot V$ & IVA & ماهيت شغل \\
\hline
\end{tabular}


حميد رحيمى | ماهيت شغلى و سازكًارى شغلى

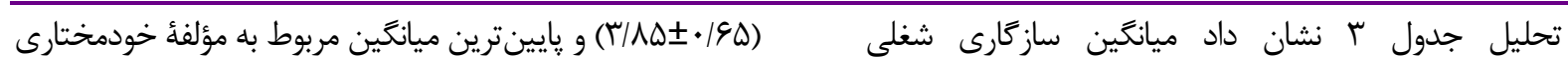

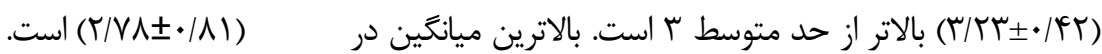

بين مؤلفههاى سازكارى شغلى، مربوط به مؤلفأ ارزش بيشرفت

جدول ب. آزمون t تكنمونهاى جهت مقايسه ميانكين ساز كارى شغلى

\begin{tabular}{|c|c|c|c|c|c|c|}
\hline $\mathbf{P}$ & درجه آزادى & $\mathbf{t}$ & ميانَين جامعه & ميانتين و انحرافاستاندارد & تعداد & متغير \\
\hline $.1 . .1$ & IVV & $I V / \Delta \Lambda$ & r & $r / \cdot \pm \wedge \Delta / \varphi \Delta$ & IVA & ارزش بيشرفت \\
\hline $.1 . .1$ & IVV & $\cdot / T R \Delta$ & r & $r / \cdot \pm / \& q$ & IVA & ارزش راحتى \\
\hline.$/ 4 \Delta$ & IVV & ./V9Q & r & $r / \cdot \pm \cdot r / v r$ & IVA & ارزش پايگاه \\
\hline $.1 . .1$ & IVV & $10 / 91$ & r & 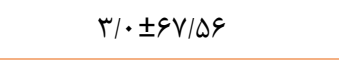 & IVA & ارزش دوستى \\
\hline $.1 . .1$ & IVV & N/99 & r & $r / \cdot \pm r A / F F$ & IVA & ايمنى \\
\hline $.1 . .1$ & IVV & r/FF & r & $r / \cdot \pm V \wedge / \wedge)$ & $I V \Lambda$ & خودمختارى \\
\hline$\cdot / \mathrm{VV}$ & IVV & $\cdot \pi$ & $r$ & $r / \cdot \pm 9 \Lambda / 9 V$ & $I V \Lambda$ & سبك سازگارى \\
\hline $.1 . .1$ & IVV & $V / T \Delta$ & r & $r / \cdot \pm r r / F r$ & IVA & سازًَارى شغلى \\
\hline
\end{tabular}

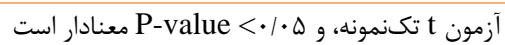

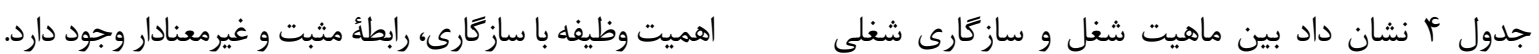

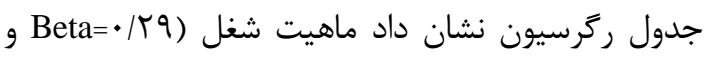

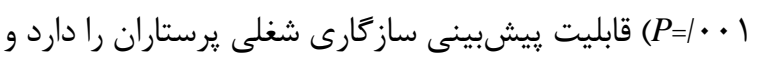

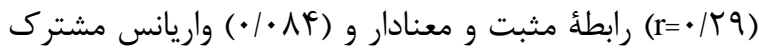

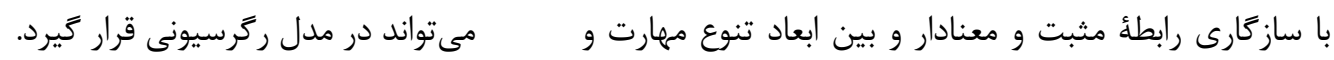

\begin{tabular}{|c|c|c|c|}
\hline $\boldsymbol{P}$ & $\mathbf{R}^{2}$ & $\mathbf{R}$ & متغير \\
\hline.$/ 11$ & .1 .14 &.$/ 14$ & تنوع مهارت و سازگارى \\
\hline$\cdot / 11$ & .1 .1 & $\cdot 11$ & اهميت وظيفه و سازحارى \\
\hline$\cdot / . .1$ & $\cdot / \pi r$ & $\cdot / 4 v$ & هويت وظيفه و سازكارى \\
\hline.$/ . .1$ &.$/ 14$ & $\cdot \pi \wedge$ & استقلال و سازَارى \\
\hline.$/ . .1$ & $\cdot / 14$ & $\cdot \pi \wedge$ & بازخورد و سازَارى \\
\hline$\cdot 1 \cdot \cdot 1$ & $\cdot / \cdot \wedge r$ & $\cdot / 49$ & ماهيت شغل و سازكارى \\
\hline
\end{tabular}

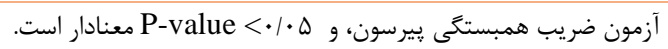

جدول ه. ضرايب ركَ سيون براى بيشبينى سازكارى شغلى از روى ماهيت شغل

\begin{tabular}{|c|c|c|c|c|c|}
\hline $\boldsymbol{P}$ & $\mathbf{t}$ & خطاى استاندارد & Beta & B & متغير \\
\hline$\cdot 1 \cdot \cdot 1$ & $\Delta F / \|$ & $\cdot 1 \cdot 9$ & - & $r / \cdot F t$ & مقدار ثابت \\
\hline $.1 \cdot .1$ & $\boldsymbol{r} / \cdot \boldsymbol{r}$ & $\cdot \mid \cdot \cdot 1$ & $\cdot / 4 q$ & 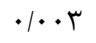 & ماهيت شغل \\
\hline
\end{tabular}

آزمون ضريب ركرسيون، و هـ/• > P-value معنادار است.

شرايط مطلوب است. اين نشان مىدهد كه از ديدكاه يرستاران، بحث

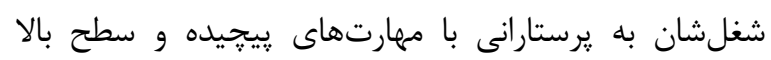

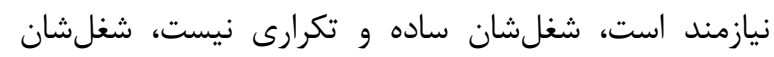

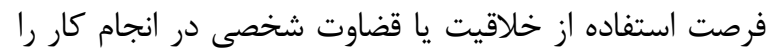

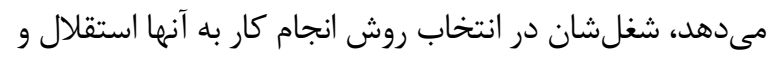

يافتهها نشان داد ميانكَين ماهيت شغلى يرستاران در ابعاد

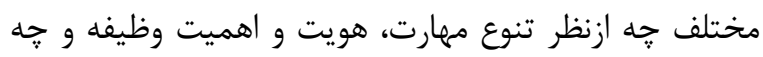

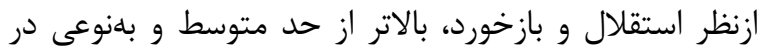




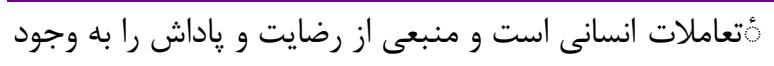

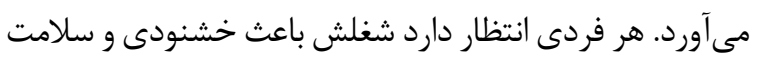

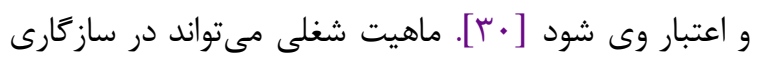

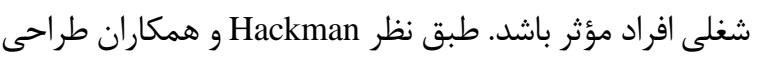

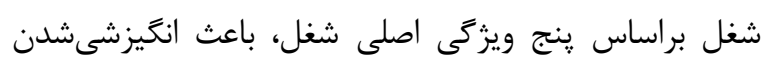

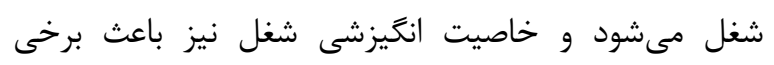
برون دادها مانند خشنودى شغلىى، تعهد شغلى، دلبستخى شغلى

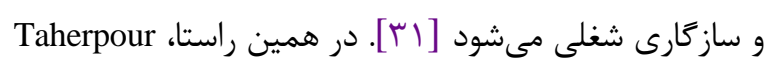
و همكاران نيز در يروهشى به اين نتيجه دست يافتند كه در

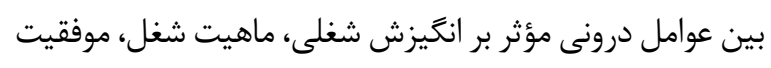

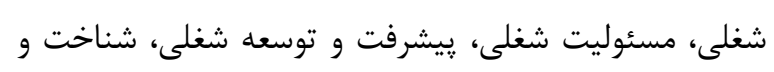
قدردانى از افراد بلترتيب بيشترين نقش را داشتند [19].

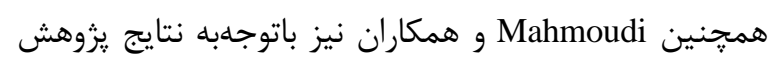

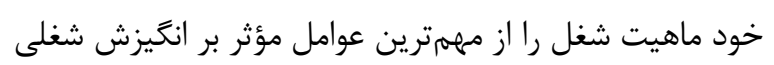
يرستاران مىدانند [IV]

ازجمله محدوديتهايى كه در اين تحقيق وجود داشت، دمدان

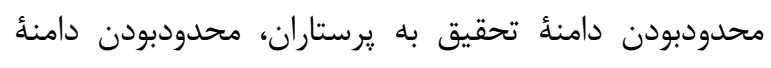
تحقيق به دانشعاه علوميزشكى كاشان و عدم امكان تعميم به دهان ساير دانشخاهها و مراكز ديخر بود. ازجمله محدوديتهاى ديخر

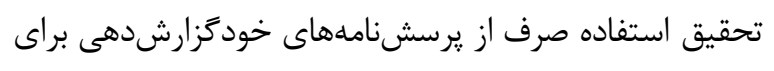

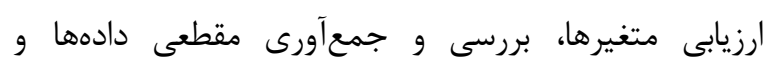
همكارىنكردن برخى از يرستاران در پاسخگويى به سؤالات

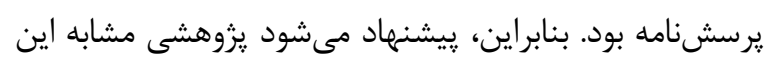

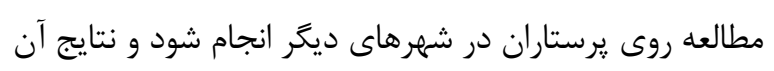

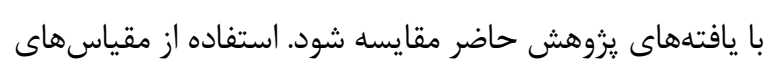

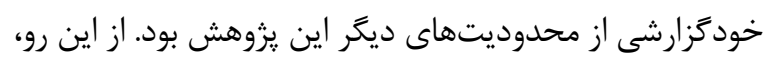

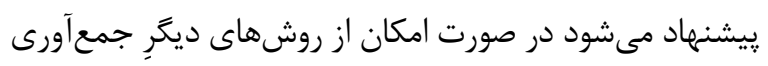
اطلاعات مانند مصاحبه و مشاهده استفاده شود تا اطلاعات كاملتر و دقيقتر به دست آيد. علاوهبر اين، ييشنههاد مى كنيهم

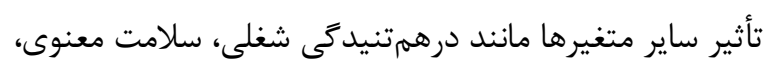

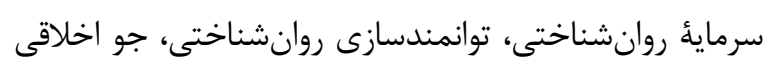

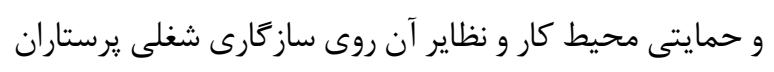

$$
\text { توسط يزوهشخران ديخر بررسى شود. }
$$

\section{نتيجه ََيرى}

طبق يافتهها، ميانخين ماهيت شغلى و سازگًارى يرستاران

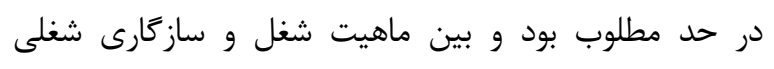

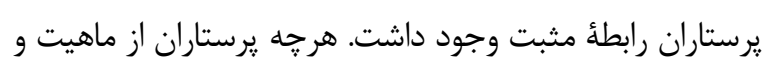
ويزگى هاى شغلى خود در ابعاد (تنوع مهارت، هويت وظيفه،
آزادى قابلتوجهى مى كدهد، شغلشان نيازمند افرادى است كه كارهاى مختلفى انجام دهد و از يكى مهارت متنوع و استعداد

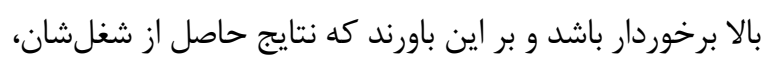

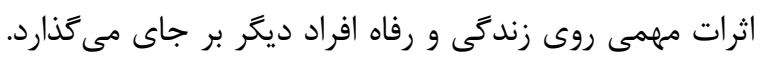

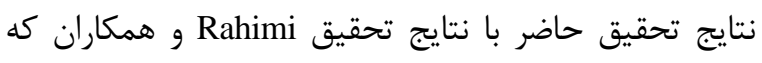

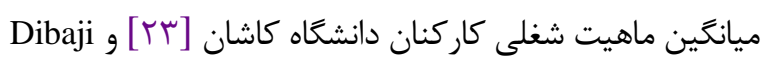

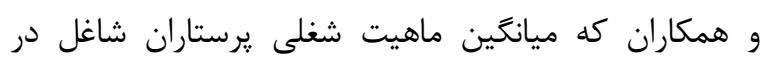
بيمارستان فوقتخصصى الزهراى اصفهان را بالاتر از حد متوسط ماني

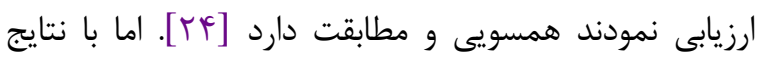
تحقيق Faraji و همكاران كه ميزان ماهيت شغلى يرستاران

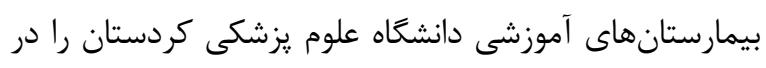

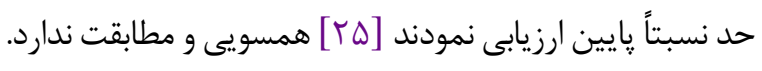

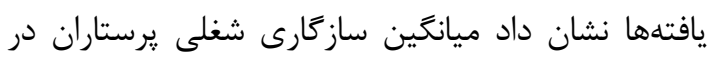

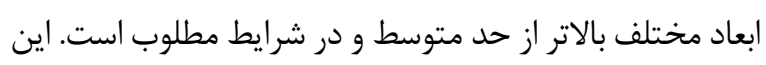

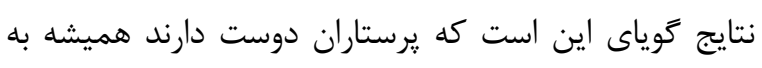

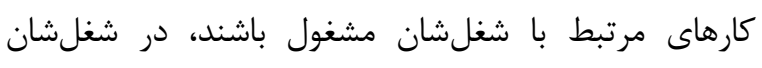

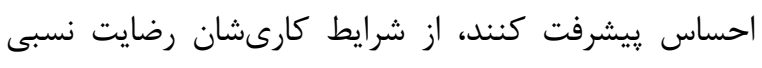
دارند، معتقدند امكان ترقى و رفتن به مراحل بالاتر وجود دارد،

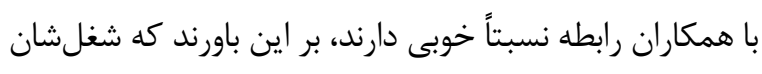

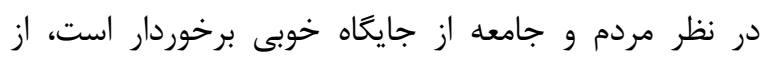
جالشهاى موجود در شغلشان لذت مىبرند و در شغلشان اقتدار نسبى و مناسبى دارند. در همين راستا، Samadifar و و

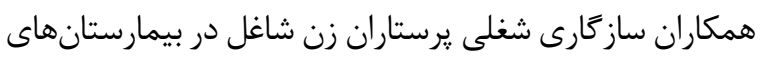

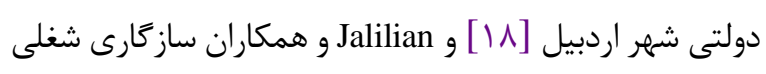

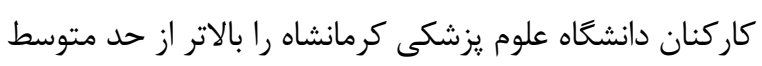

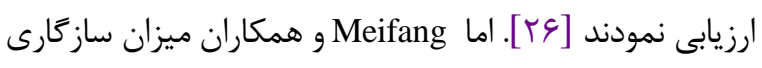

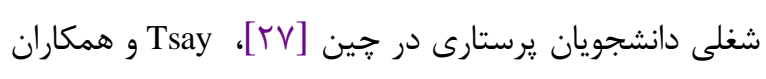

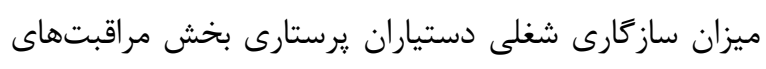

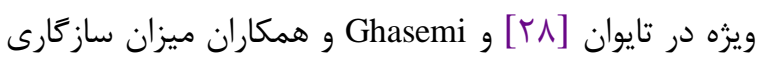
شغلى يرستاران مراكز آموزشى درمانى شهر زنجان ران رايانين

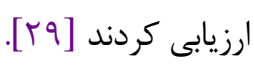
طبق نتايج بين ماهيت شغل و ابعاد آن با سازگًارى شغلى ردئ

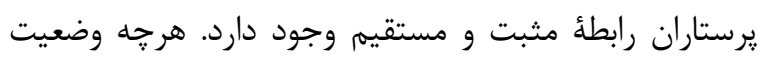
ماهيت شغلى و مطلوبيت آن نزد يرستاران بيشتر باشد به همان

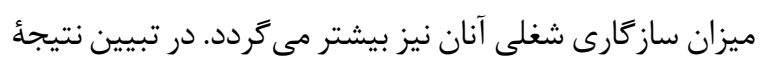

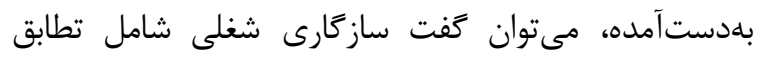
شخصيت فرد با عوامل محيطى كار است. نظرية ساز

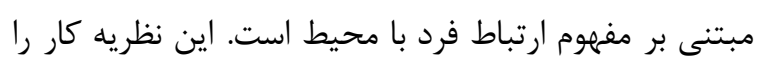
جيزى بيش از فرايندهاى وظيفهمدار مى داند كه در بركيرنده 


\begin{tabular}{|c|c|}
\hline & حميد رحيمى | ماهيت شغلى و سازكارى شغلى \\
\hline تقدير و تشكر & اهميت وظيفه، استقلال و بازخورد) رضايت بيشتر و مطلوبيت \\
\hline نويسنده از همهٔ مسئولان و يرستاران بيمارستانهاى شهر & بالاترى داشته باشند ميزان سازحارى شغلى آنها بيشتر شده و \\
\hline كاشان كه در يزوهش حاضر همكارى كردند تشكر و قدردانى & بالتبع عملكرد شغلىشان نيز بهبود يِدا خواهد كرد. علاوهبر اين، \\
\hline مىنمايد. مقالهٔ حاضر بركرفته از يزوهش مصوب در شوراى & براى كاهش استرس و افزايش سازحارى بيشتر يرستاران، مديران \\
\hline تخصصى يزوهشى دانشخاه علوميزشكى و خدمات & بايد توجه بيشترى به ادراكات يرستاران از ويزگكى هاى شغلىشان \\
\hline 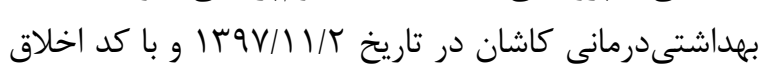 & داشته باشند و تنوع، بازخورد و فرصت ايجاد روابط دوستانه در \\
\hline IR.KAUMS.NUHEPM.REC.1397.059 است. & شغل را براى آنان فراهم كنند. جون ماهيت شغلى با برخى \\
\hline & رفتارهاى مطلوب كاركنان همجون عملكرد شغلى، تعهد شغلى، \\
\hline 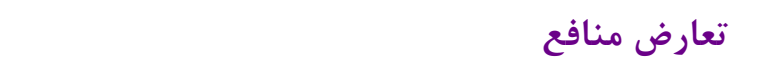 & ترك شغل و سازكارى شغلى در ارتباط هستند، مىتوان از نتايج \\
\hline بين نويسندكان هيجَّونه تعارضى در منافع وجود ندارد. & 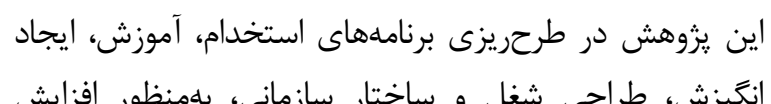 \\
\hline منابع مالى & سازكًارى شغلى يرستاران استفاده كرد. \\
\hline
\end{tabular}

منابع مالى اين مطالعه توسط نويسندًان تامين شده است.

\section{References}

1. Tabataba'i-Nasab SM, Sabokro M, Fallahi MB. The effect of psychological capital on work engagement with mediating role of work -family conflict among nurses. Nurs Manag. 2017; 6(1):20-31. (In Persian) [DOI:10.29252/ijnv.6.1.20]

2. Chien WT, Yick S. An investigation of nurses' job satisfaction in a private hospital \& its correlates. Open Nurs J. 2016; 10:99-112. [DOI: 10.2174/1874434601610010099] [PMID] [PMCID]

3. Kelbiso L, Belay A, Woldie M. Determinants of quality of work life among nurses working in Hawassa Town Public Health Facilities, South Ethiopia: a cross-sectional study, Nurs Res Pract. 2017:5181676. PMCID: PMC5742902. [DOI:10.1155/2017/5181676] [PMID] [PMCID]

4. Liaschenko J, Peter E. Fostering nurses' moral agency and moral identity: the importance of moral community, Hastings Cent Rep, 2016; 46(1):18-21. [DOI:10.1002/hast.626] [PMID]

5. Akbari Fard S. The relation multiple intelligence and personality types with job adjustment in teachers at secondary schools. MA thesis in University of Allame Tabatabaei. 2009. (In Persian)

6. Nezami A, Givarian H. An investigation of the effect of psychological capital on the burnout of nurses in a military hospital in Tehran. Ebnesina. 2016; 18(1):4451. (In Persian)

7. Seyyed Ameri MH, Saeidi Sh. The relationship between role clarity and job compatibility of employees in sport and youth offices of Western Azerbaijan Province. Res Sport Phys Manag. 2014; 6(3):107-116. (In Persian)

8. Hajian A, Sheykholeslami M, Homaei R, Mohammadi S, Kheirabadi Gh. The relation between role clarity \& role adjustment. Res Behav Sci. 2012; 10(6):520-5. (In Persian)

9. Dawis RV, Lofquist LH. A psychological theory of work adjustment. Minneapolis, MN: University of Minnesota Press; 1984.

10. Chang TY, Chang TL. Relationship between role stress and job clarity in sales people employed by travel agents in Tiwan. Int J Stress Manag. 2012; 14(2):211-23. [DOI:10.1037/1072-5245.14.2.211]

11. Azarpira G, Yaghobi A, Forghani M, Soleymani G. The relationship between role clarity and job compatibility in the Sport \& Physical Education Office. Int J Sport Stud. 3(2):194-8. (In Persian)

12. Azizi M, Ghoudarzi Z, Rafiee N. Assessing the relation between organization climate and job nature with staffs' job motivation in Isfahan Hospitals. JHOSP. 2015; 14(2):111-8. (In Persian)

13. Nasrabadi HA, Rajaeepour S, Salimi Gh, Taherpour F, Partovi H. The study of relation between job nature and job satisfaction. Execut Manag. 2009; 9(1):58-76. (In Persian)

14. Hackman JR, Oldham GR. Motivation through the design of work: test of a theory. Organ Behav Human Perform. 1975; 16:250-79. [DOI:10.1016/00305073(76)90016-7]

15. Jodat S, Farajzadeh Z, Saadatjoo SA. A study of job motivation of nurses working in Valiasr Hospital of Birjand in 2013. Mod Care Sci Q Birjand Nurs Midwifery Fac. 2014; 10(4):296-304. (In Persian)

16. Taherpour M, Sefidi F, Javadi A. Factors affecting the motivation of the members of the Board of Qazvin University of Medical Sciences. Dena Quart. 2015; 6:21-2. (In Persian)

17. Mahmoudi H, Ebrahimian A, Solymani M, Ebadi A. The study of job motivation factors in critical care nurses, Behav Sci. 2008; 1(2):171-8. (In Persian)

18. Samadifard HR, Narimani M. The relationship between moral identity, spiritual well-being and religious orientation with job adjustment among Nurses. PSJ. 2018; 17(1):1-8. (In Persian) [DOI:10.21859/psj.17.1.1]

19. Akbar Bagloo M, Valizadeh L. Job stress and adjustment methods in nurses working in the psychiatric part of Razi Hospital in Tabriz. Modern Care Journal. 2011; 8(1):45-51. (In Persian)

20. Hackman JR, Oldham GR. Motivation through the design of work: Test of a theory. Organ Behav Human 
Perform, 1976; 16(2):250-79. [DOI:10.1016/00305073(76)90016-7]

21. Lawshe $\mathrm{CH}$. A quantitative approach to content validity. Personnel Psych. 1975; 28, 563-75. [DOI:10.1111/j.1744-6570.1975.tb01393.x]

22. Munro BH. Statistical Methods for Health Care Research, Philadelphia: New Jersey: Lippincott Williams \& Wilkins; 2004; P. 105.

23. Rahimi H, Esmaili M. The effect of work ethic and job identity on job involvement in staffs at University of Kashan. J Industry Uni. 2018; 11(39):53-64. (In Persian)

24. Dibaji S, Shahpoori S, Nouri A. The role of job characteristics in nurses' willingness to customeroriented behaviors. IJN. 2013; 26(83):30-8. (In Persian)

25. Faraji A, Valiee S, Mazidi G, Ramazanh A, Rezaee Farahani M. Relationship between job characteristic and job stress in nurses of Kurdistan University of Medical Sciences Educational Hospitals. IJNR. 2012; 7(25):54-63. (In Persian)

26. Jalilian S, Karimianpour G. The relationship between psychological capital and job adjustment of staffs in Kermanshah University of Medical Sciences. PSJ. 2018; 16(3):39-47. (In Persian) [DOI:10.21859/ps].16.3.39]

27. Meifang Hu, Yinjun Z. Nursing students' adjustment and coping strategies in clinical practice. MA thesis in Nursing, Nursing Department Medicine and Health College. China: Ishui University.

28. Tsay S, Wen-Yi C, Yu-Hui L, Yia-Wun L. Job stressors, work adjustment and intention to leave: A study of female nursing assistants in long-term care facilities in Taiwan. Taiwan J Public Health. 2013; 32(5):476-490.

29. Ghasemy M, Mortaghy M, Ghahremani Z, Vahediane Azimi A, Ghorbani F. Nurses job stress in Therapeutic Educational Centers in Zanjan. J Res Dev Nurs Midw. 2011; 8(1):42-51. (In Persian)

30. Sohrabian A, Modaresi S, Yousefi F. The investigation of relationship between organizational climate and job satisfaction among occupied Nurses in Psychiatric Hospitals of Qods, Tohid and Besat. Shenakht J Psych Psychiat. 2018; 4(4):34-43. (In Persian)

31. Hackman, JR, Lawler EE. (2007). Employee reaction to job characteristics. J Appl Psych. 2007; 55(3):25986. [DOI:10.1037/h0031152] 